\title{
Optimization of the heat treatment of additively manufactured Ni-base superalloy IN718
}

\author{
Benedikt Diepold ${ }^{1)}$, Nora Vorlaufer ${ }^{1)}$,Steffen Neumeier ${ }^{1)}$, Thomas Gartner ${ }^{2)}$, and Mathias Göken ${ }^{1)}$ \\ 1) Department of Materials Science \& Engineering, Institute I, Friedrich-Alexander-Universität Erlangen-Nürnberg, Erlangen 91058 , Germany \\ 2) Lufthansa Technik AG, Hamburg 22335, Germany \\ (Received: 6 December 2019; revised: 27 January 2020; accepted: 1 February 2020)
}

\begin{abstract}
Additive manufacturing (AM) of Ni-base superalloy components can lead to a significant reduction of weight in aerospace applications. AM of IN718 by selective laser melting results in a very fine dendritic microstructure with a high dislocation density due to the fast solidification process. The complex phase composition of this alloy, with three different types of precipitates and high residual stresses, necessitates adjustment of the conventional heat treatment for AM parts. To find an optimized heat treatment, the microstructures and mechanical properties of differently solution heat-treated samples were investigated by transmission and scanning electron microscopy, including electron backscatter diffraction, and compression tests. After a solution heat treatment (SHT), the Nb-rich Laves phase dissolves and the dislocation density is reduced, which eliminates the dendritic substructure. SHT at 930 or $954^{\circ} \mathrm{C}$ leads to the precipitation of the $\delta$-phase, which reduces the volume fraction of the strengthening $\gamma^{\prime}$ - and $\gamma^{\prime \prime}$-phases formed during the subsequent two stage aging treatment. With a higher SHT temperature of $1000^{\circ} \mathrm{C}$, where no $\delta$-phase is precipitated, higher $\gamma^{\prime}$ and $\gamma^{\prime \prime}$ volume fractions are achieved, which results in the optimum strength of all of the solution heat treated conditions.
\end{abstract}

Keywords: Ni-base superalloy; selective laser melting; strengthening mechanism; powder bed fusion; microstructure

\section{Introduction}

Components with reduced weight and integrated functional features for aerospace applications can be produced by additive manufacturing (AM). Examples include the cabin bracket for the turbine of Airbus A350 XWB [1] or designs of additively manufactured liquid propellant injectors for future rocket engines by the Ariane Group [2]. Although such components are already in use, the correlation between processing, subsequent heat treatments and the resulting microstructures and mechanical properties of additively manufactured alloys, such as the Ni-base superalloy IN718, is still not well understood.

IN718 is often used for AM because it exhibits excellent mechanical properties, has good weldability, and thus has minor problems with thermally-induced cracks [3-4]. The fast solidification on the order of $10^{-2} \mathrm{~s}$ combined with high thermal gradients of around $10^{7} \mathrm{~K} / \mathrm{m}$ leads to residual stresses [5-6], which may result in unexpected deformation after separation of the part from the base plate [7]. High local residual stresses can also cause hot cracking, primarily at the grain and melt pool boundaries due to the low crack susceptibility of as-built IN718 [8-9]. A reduction of residual stresses can be achieved by preheating the base plates [10-11]. However, a fine dendritic microstructure is formed due to high thermal gradients $(G)$ and high solidification rates $(R)$ [12]. Depending on the $G / R$ ratio, the dendrites are either columnar or equiaxed/cellular [12-13]. The dendritic structure coincides with a high dislocation density at the cell boundaries [14-17]. Thus, the as-built condition is strengthened by the high dislocation density and the fine microstructure, which leads to the dislocation and Hall-Petch hardening mechanism [18-22]. However, no $\gamma^{\prime \prime}$ - and $\gamma^{\prime}$-precipitates are formed during fast solidification. Thus, the as-built condition usually exhibits lower mechanical properties than the heat-treated condition. In order to form these strengthening precipitates and optimize the phase fractions of all precipitates, an adjustment to conventional heat treatments of additively manufactured material is necessary. In IN718, the finely dispersed, disc shaped $\gamma^{\prime \prime}$-precipitates $\left(\mathrm{Ni}_{3} \mathrm{Nb}, \mathrm{DO}_{22}\right)$ and $\gamma^{\prime}$-precipitates $\left(\mathrm{Ni}_{3}(\mathrm{Al}, \mathrm{Ti})\right.$, $\mathrm{L1}_{2}$ ) form during a two stage aging treatment and contribute to the high strength of the alloy $[14,23]$. The aging treatment 
is usually conducted as a two stage aging treatment at $620^{\circ} \mathrm{C}$ for $8 \mathrm{~h}$ followed by $720^{\circ} \mathrm{C}$ for $8 \mathrm{~h}[15,20,24]$. A prior solution heat treatment (SHT) between 930 and $1070^{\circ} \mathrm{C}$ can dissolve the detrimental Laves phase, homogenize the $\mathrm{Nb}$-content and reduce residual stresses. At the lower half of this temperature range, the $\delta$-phase $\left(\mathrm{Ni}_{3} \mathrm{Nb}, \mathrm{D} 0_{\mathrm{a}}\right)$ precipitates, which is necessary to avoid grain growth during the conventional cast and wrought processing route. Since the $\delta$-phase has the same chemical composition as the $\gamma^{\prime \prime}$-phase, less $\gamma^{\prime \prime}$ can be formed during the aging heat treatment, which then might reduce the mechanical properties. In this work, the microstructures of a directly aged condition and three differently SHT conditions were investigated and compared with the as-built state. The correlation between the microstructure and room temperature strength was investigated to determine an optimized heat treatment for additively manufactured IN718.

\section{Experimental}

\subsection{Materials, selective laser melting process and heat treatments}

The AM process of the samples was carried out on an EOS M 290 selective laser melting (SLM) machine (EOS $\mathrm{GmbH}$, Munich, Germany) with a layer thickness of $40 \mu \mathrm{m}$ and standard process parameters of the company EOS $\mathrm{GmbH}$. Gas atomized powder of the nickel-base superalloy IN718 was used. The composition, according to the supplier (EOS GmbH, Munich, Germany), is shown in Table 1. The median diameter of the powder particles was $29.5 \mu \mathrm{m}$ and $10 \%$ of the powder particles were smaller than $18.5 \mu \mathrm{m}$. The platform was preheated to $80^{\circ} \mathrm{C}$. A rod, whose axis was perpendicular to the building direction, with a diameter of 10 $\mathrm{mm}$ and a support structure in the middle of the base plate was analyzed.

The as-built condition and four heat-treated states were examined. Three different SHTs with a maximum temperature of $930^{\circ} \mathrm{C}$ (named SHT930), $954^{\circ} \mathrm{C}$ (named SHT954), and $1000^{\circ} \mathrm{C}$ (named SHT1000) were held for $1 \mathrm{~h}$. The samples were then water quenched. Afterwards, all solution heat treated samples as well as samples for direct aging were subjected to an aging treatment at $720^{\circ} \mathrm{C} / 8 \mathrm{~h}$ and $620^{\circ} \mathrm{C} / 8 \mathrm{~h}$ to form the strengthening $\gamma^{\prime}$ - and $\gamma^{\prime \prime}$-precipitates. The cooling rate between the first and second stage of the age treatment was $38^{\circ} \mathrm{C} / \mathrm{h}$ for the SHT954 condition and $50^{\circ} \mathrm{C} / \mathrm{h}$ for all of the others. The heat treatments were performed in a box-type furnace ME 8/13 (Helmut Rohde GmbH, Prutting, Germany) in an air atmosphere. The temperature-time curves of all conducted heat treatment procedures are shown in Fig. 1.

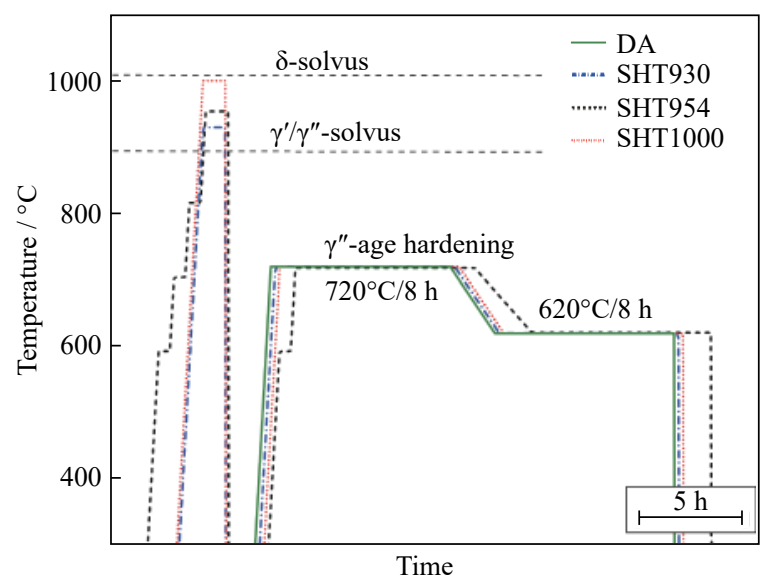

Fig. 1. Procedures of the three conditions with SHTs and aging as well as one direct aged (DA) condition of additively manufactured IN718.

Table 1. Composition of IN718 produced by selective laser melting

\begin{tabular}{|c|c|c|c|c|c|c|c|c|c|c|c|}
\hline $\mathrm{Ni}$ & $\mathrm{Cr}$ & $\mathrm{Nb}$ & Mo & $\mathrm{Ti}$ & Al & $\mathrm{Si}$ & Co & $\mathrm{Mn}$ & $\mathrm{Cu}$ & $\mathrm{C}$ & $\mathrm{Fe}$ \\
\hline $50-55$ & $17.0-21.0$ & $4.75-5.50$ & $2.80-3.30$ & $0.65-1.15$ & $0.20-0.80$ & $\leq 0.35$ & $\leq 1.00$ & $\leq 0.35$ & $\leq 0.30$ & $\leq 0.08$ & Bal. \\
\hline
\end{tabular}

\subsection{Sample preparation and characterization}

Thin samples were cut from the rods using a precision cutting machine. Cross sections parallel and perpendicular to the building direction (BD) of the different conditions were examined by microstructural analysis. All samples were ground to a grit size of 2500 , mechanically polished using a 3 $\mu \mathrm{m}$ diamond suspension and electrochemically polished in electrolyte A2 (Struers GmbH, Willich, Germany). The asbuilt state was etched with Kalling 2 reagent. A scanning electron microscope (SEM, Zeiss Crossbeam 1540 ESB, Germany) was used for the examination. The micrographs were recorded using the back scattered electron contrast mode (BSE) with a working distance of around 7-8 $\mathrm{mm}$ at a voltage of $20 \mathrm{kV}$. The $\delta$-fractions of the solution heat treated conditions were determined using the trainable Weka segmentation plugin of Image J 1.51 (National Institutes of Health, USA). This open-source plugin generates higher accuracy of the automated detection of bright phases because an exact gray scale value does not have to be determined manually. Instead, the plugin compares the different brightness level between precipitations and the surrounding matrix.

In addition to the phase fraction analysis, the grain orientation and morphology of the as-built, direct-aged, SHT954, and SHT1000 conditions parallel to the BD were investigated using electron backscatter diffraction (EBSD). The measurements were performed on a Zeiss Crossbeam 540 SEM. Furthermore, high resolution EBSD-mappings of the as-built and SHT1000 condition were conducted with a width 
of $5 \mu \mathrm{m}$. Therefore, the binning of the detector was set to $4 \times$ 4 to reduce drift issues and the step size was set to $0.025 \mu \mathrm{m}$. The data was analyzed using misorientation mappings, where the pixels were colored according to their orientation differences to their neighbor. For transmission electron microscopy (TEM) investigations, a foil of the SHT954 condition with a thickness of $150 \mu \mathrm{m}$ was twinjet polished using A2 electrolyte at $-30^{\circ} \mathrm{C}$. The sample was investigated using a TEM (Philips CM200).

\subsection{Compression tests}

Cylindrical samples with a diameter of $4 \mathrm{~mm}$ and a length of $6 \mathrm{~mm}$ were cut out of the differently heat-treated rods by electric discharge machining. The cylinders were ground plane-parallel to a grit size of 4000 . The compression tests were performed on an Instron 4505 testing machine with a strain rate of $10^{-4} \mathrm{~s}^{-1}$ up to a deformation of $13 \%$. The yield strength was determined at a plastic strain of 0.02 .

\section{Results}

\subsection{Microstructures, phase composition and dislocation density of the different heat treated conditions}

The microstructures of the SLM material in different conditions are shown in Fig. 2. The original melt pool boundaries and fine dendritic structure are observed in the etched sample of the as-built state (Fig. 2(a)). The columnar dendrites are often tilted in reference to the BD. These dendrites can be cut either parallel or perpendicular to their axis and form elongated or cellular structures in the 2D images parallel to the BD (Fig. 2(b)). However, some of the cells with an average diameter of around $0.71 \mu \mathrm{m}$ are equiaxed dendrites. The cell boundaries appear bright in the BSE contrast due to $\mathrm{Nb}$ enrichment and the formation of $\mathrm{Nb}$-rich Laves phases [25].

The formation of strengthening $\gamma^{\prime}$ - and $\gamma^{\prime \prime}$-precipitates by a two stage aging treatment at 720 and $620^{\circ} \mathrm{C}$ is necessary to obtain a maximum strength of IN718 alloy. The microstructure of the direct aged (DA) condition is compared to the asbuilt condition in Fig. 2. The SEM micrographs show no significant changes between the as-built and DA condition. The fine columnar and equiaxed dendritic structures are preserved at the relatively low aging temperatures. The significant differences of the $\gamma^{\prime}$ - and $\gamma^{\prime \prime}$-precipitates cannot be observed in the SEM images due to their small size. Figs. 2(d)-2(f) show the microstructures of the solution heat treated and aged conditions. The SHT between 930 and $1000^{\circ} \mathrm{C}$ dissolved the brittle Laves phases. The Nb-rich substructures vanished and thus, the $\mathrm{Nb}$ content was homogenized. This can be especially observed in the SHT1000 condition. In addition, depending on the SHT temperature, a bright $\delta$-phase was precipitated. In the case of the SHT930 and SHT954 conditions, thicker $\delta$-plates formed at the grain boundaries and finer cross-hatched $\delta$-plates formed in the grain interior. However, the fraction of the $\delta$-phase in the SHT930 condition of $13.9 \mathrm{vol} \%$ is clearly greater than that in the SHT954 condition of $5.4 \mathrm{vol} \%$. The high fraction of thin $\delta$-plates within the grain interior could also have a precipitation strengthening effect, however, their formation also led to a lower fraction of the more potent precipitation strengthening $\gamma^{\prime \prime}$ phase, as will be discussed later. The SHT1000 condition contains only a very small amount of the $\delta$-phase that precipitated at grain boundaries because the heat treatment temperature of $1000^{\circ} \mathrm{C}$ is near the $\delta$-solvus temperature of $1010^{\circ} \mathrm{C}[26]$. Thus, the amount of the $\delta$-phase is approximately $0.7 \mathrm{vol} \%$. Fig. 3 shows the EBSD mappings along the $\mathrm{BD}$ of the as-built condition compared to the DA, the $\delta$-rich SHT954 and $\delta$-poor SHT1000 conditions. There is no discernible difference among the different heat treatments. The grains have a crescent-shaped and elongated morphology due to the rounded melt pool geometry caused by the Gaussian distributed power of the laser spot during the manufacturing process. An orientation map is shown in Fig. 3(e) for the asbuilt condition, which is similar to the other conditions. The SLM material exhibits a light texture. Approximately 1.5 times more grains are oriented at a tilt angle of $5^{\circ}-10^{\circ}$ to $<001>$, compared to a total random distribution. The median grain diameter of the SLM material is around $14 \mu \mathrm{m}$. Since the temperature of all conducted heat treatments was below the recrystallization temperature, neither grain coarsening nor texture change occurred.

EBSD measurements were performed on the as-built and SHT1000 heat treated condition for gain qualitative data regarding the dislocation density. The misorientation mappings of both conditions and SEM images of the corresponding areas are shown in Fig. 4. In the as-built condition, small misorientation angles of up to $2^{\circ}$ are observed at all cell boundaries as well as slight misorientations randomly distributed over the entire examined region. This indicates that the cell boundaries and their interiors contain a high dislocation density. The heat treated condition shows the formation of sharper cell boundaries and larger regions with the same orientation. The nearly homogeneous blue color indicates that a lower dislocation density remains in the interior. This corresponds with the BSE image, where the boundaries of coarsened cell structures are very distinct (see Fig. 3(d)).

TEM investigations revealed the formation of $\gamma^{\prime}$ - and $\gamma^{\prime \prime}$ precipitates during the aging treatment. Fig. 5(a) shows the diffraction pattern of the SHT954 condition, oriented along the $[001]_{\gamma}$ zone axis. The bright fundamental reflections belong to the $\gamma$-matrix and the fine superlattice reflections belong to the $\gamma^{\prime}$ - and $\gamma^{\prime \prime}$-precipitates. By selecting the marked spot, which is an overlap of the (001) reflection of $\gamma^{\prime}$ and (002) reflection of disc-shaped $\gamma^{\prime \prime}$, the precipitates can be observed in the dark field image, as shown in Fig. 5(b). The disc-shaped $\gamma^{\prime \prime}$-precipitates have a length of around 5-20 nm. 

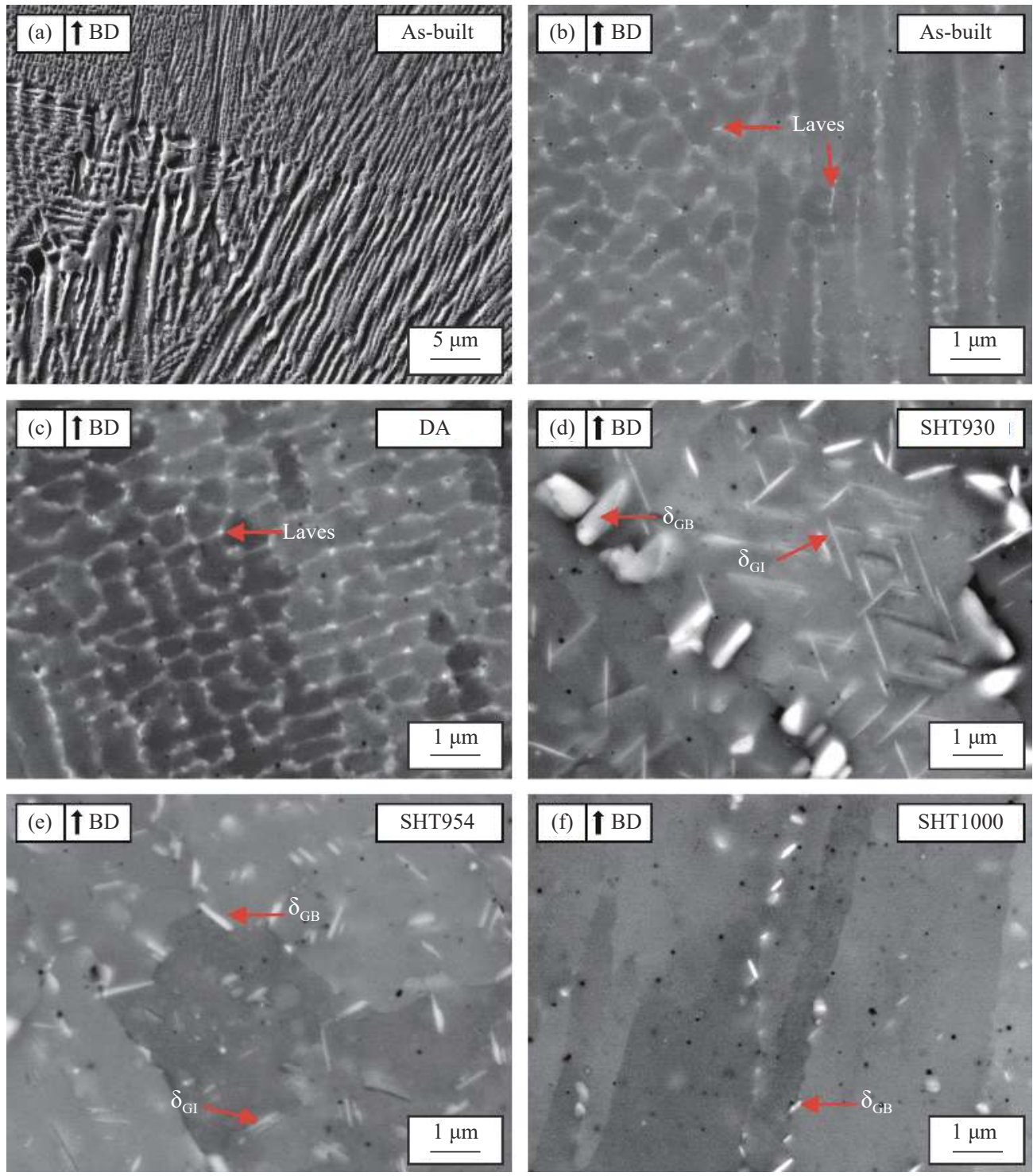

Fig. 2. Microstructures of the as-built condition and the four different heat-treated conditions: (a) etched as-built condition; (b) electro-polished as-built and (c) DA condition showing $\mathrm{Nb}$ rich dendritic cell boundaries and the formation of the Laves phase; (d) SHT930 condition without cells and a high amount of $\delta$-precipitates at the grain boundaries $\left(\delta_{\mathrm{GB}}\right)$ and in the grain interior $\left(\delta_{\mathrm{GI}}\right)$; (e) SHT954 condition with a moderate amount of $\delta$-phase; (f) SHT1000 condition with nearly no $\delta$-phase.

Many $\gamma^{\prime \prime}$-precipitates appear next to each other, which suggests the presence of a sandwich like $\gamma^{\prime \prime} / \gamma^{\prime} / \gamma^{\prime \prime}$ compound structure $[23,27-28]$. In the present study, no preferred orientation of $\gamma^{\prime \prime}$ can be observed, which is in contrast to the study by Zhang et al. on cold rolled IN718 [29].

\subsection{Compression strength of the different heat treated conditions}

The compression strength of the five different conditions was examined (see Figs. 6(a) and 6(b)). The as-built condition has a compressive yield strength $R_{\mathrm{P} 0.2}$ of $(895 \pm 14) \mathrm{MPa}$ ( $R_{\mathrm{P} 0.2}$ is the $0.2 \%$ offset yield strength, i.e. the amount of stress that will result in a plastic strain of $0.2 \%$ ). The highest strength is obtained for the DA condition $\left(R_{\mathrm{P} 0.2}=(1377 \pm 4)\right.$
MPa). In contrast to the as-built condition, $\gamma^{\prime}$ - and $\gamma^{\prime \prime}$-precipitates were formed during the aging treatment, which contribute to the high strength. SHT conditions cannot reach the strength of the DA condition. The SHT1000 reaches a yield strength of $(1326 \pm 2) \mathrm{MPa}$ since the highest $\gamma^{\prime \prime}$ volume fraction is present due to the dissolution of the $\mathrm{Nb}$-rich Laves phases and the homogenization of $\mathrm{Nb}$-rich interdendritic regions. Because of the higher $\delta$-fraction and the same chemical composition of the $\delta$ - and $\gamma^{\prime \prime}$-phase $\left(\mathrm{Ni}_{3} \mathrm{Nb}\right)$, the SHT930 and SHT954 conditions exhibit only moderate strength. The higher SHT temperature of the SHT954 condition leads to a slightly higher compression yield strength of $(1224 \pm 5) \mathrm{MPa}$ compared to the (1209 \pm 2$) \mathrm{MPa}$ of the SHT930 condition because less $\delta$-phase was formed leading to higher $\gamma^{\prime \prime}$ volume 

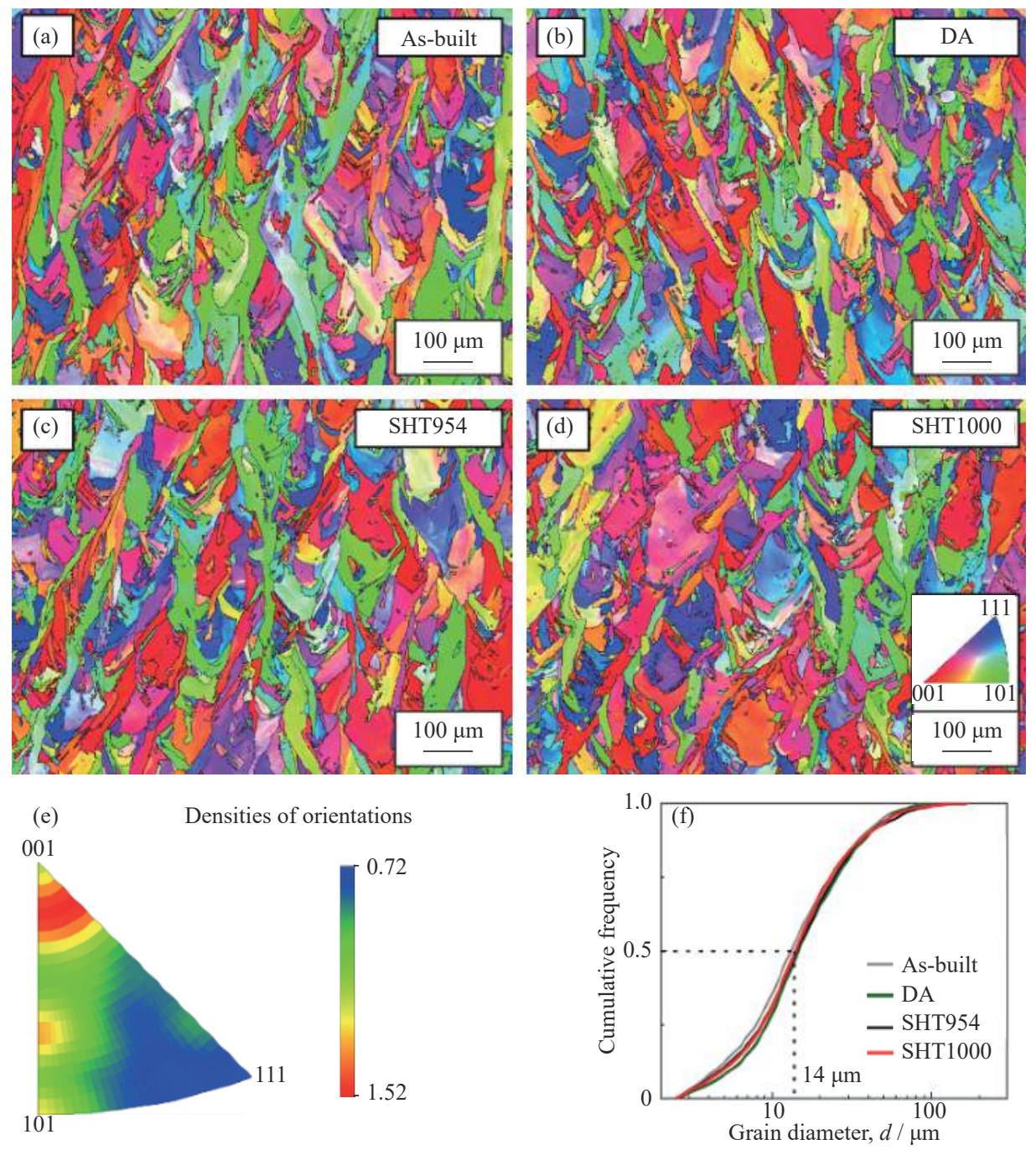

Fig. 3. EBSD mappings showing the grain morphology and orientation in the inverse pole figure (IPF) colouring for different heat treated conditions: (a) as-built; (b) DA; (c) SHT954 as a $\delta$-rich condition; (d) SHT1000 as a $\delta$-poor condition. (e) Orientation density for the as-built condition and (f) the cumulative frequency of the grain diameter of the four conditions.

fractions.

\section{Discussion}

The layer- and track-wise manufacturing process with its high temperature gradients and solidification rates determines the microstructure of a material. Depending on the temperature gradient $G$ and growth rate $R$ during the SLM process, the melt solidified in either a columnar dendritic or equiaxed dendritic structure [13,30]. Based on the two-dimensional SEM figures (Figs. 2(a) and 2(b)) it is questionable whether the cellular structures are equiaxed dendrites or rather cut along their axis columnar dendrites. The assumption of cut columnar dendrites is supported by the fact that dendrites grow often with a tilt angle up to $25^{\circ}$ against the building direction, which is observed in Fig. 2(a). Micrographs, which cut these dendrites, will show a cellular struc- ture. However, based on previous studies, equiaxed dendrites can be formed especially in the upper region of melt pools [31]. Solidified microstructures, which are similar to the observed microstructures in this study, were predicted by simulation [5,32] and have been experimentally investigated in various publications [22,33-34]. Besides the segregation of heavier elements and the formation of Laves phases, an increased dislocation density was observed at the dendritic cell boundaries. Local misorientation mappings of the as-built condition indicated high dislocation densities at the boundaries of the cells as well as lower densities in their interior (Fig. 4(a)). These results are in good accordance to the investigations of Pröbstle et al. [14], which proved high dislocation densities by TEM analysis. Due to the strengthening effect of the dislocations and small angle boundaries, the as-built condition already exhibits a high yield strength of $(895 \pm 14)$ $\mathrm{MPa}$. The microstructure of the as-built condition as well as 

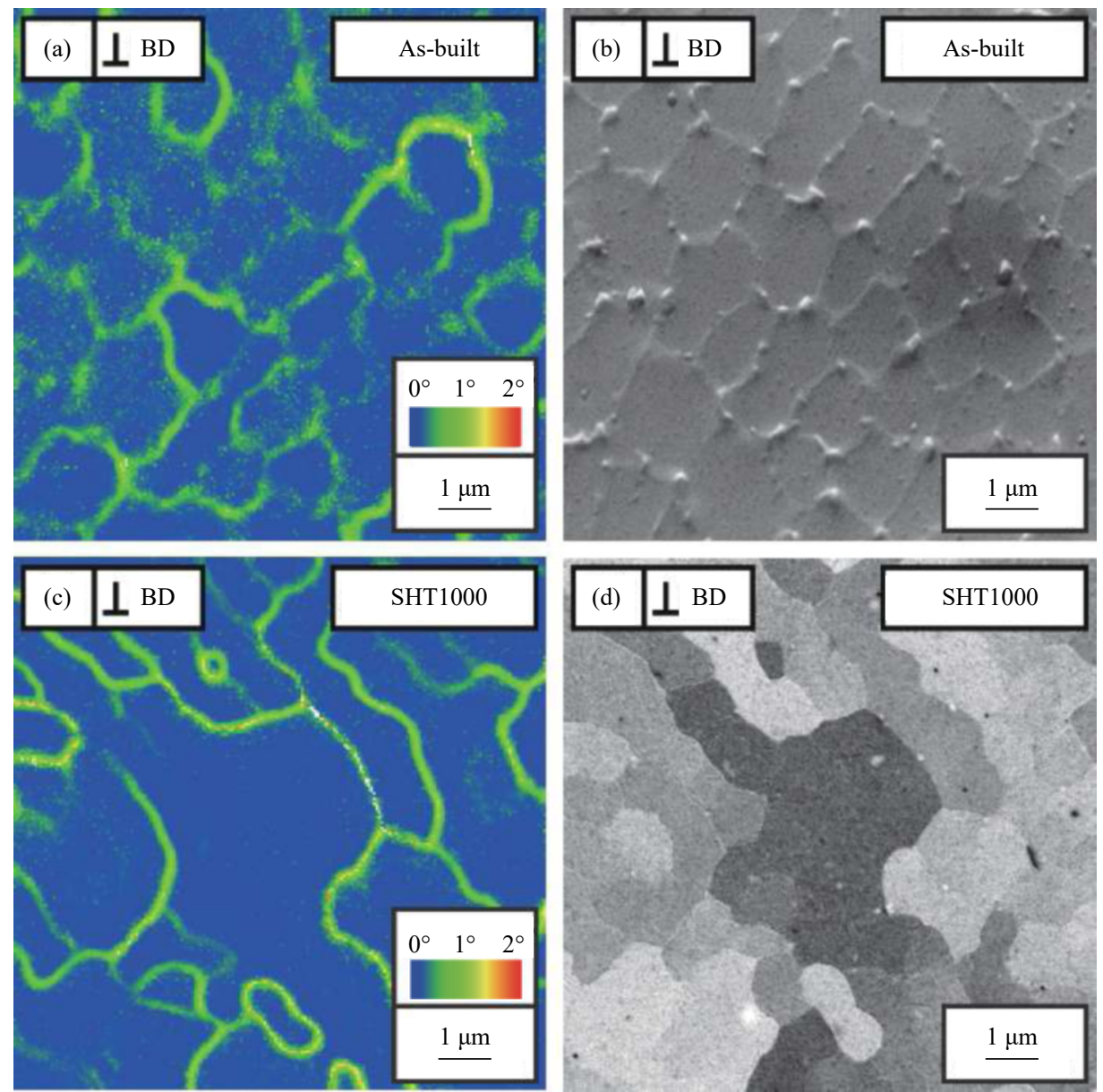

Fig. 4. Local misorientation mappings as an indicator for the dislocation density of the (a) as-built condition and (c) SHT1000 condition as well as $(b, d)$ the corresponding SEM images.

the microstructural evolution with different heat treatments is shown in the upper part of Fig. 7.

The full potential of IN718 with its complex precipitation behavior can only be reached by heat treatments that are also necessary to reduce residual stresses to avoid the formation of cracks, especially for larger components. Three different heat treatments were examined in this work and its influence on the microstructure is shown schematically in the lower part of Fig. 7. As shown in the SEM investigations, direct aging preserves the fine dendritic substructure, the high dislocation density and the Laves phase of the as-built condition, while additional strengthening $\gamma^{\prime}$ - and $\gamma^{\prime \prime}$-precipitates are formed. Thus, the highest yield strength (1377 MPa), as shown in Fig. 6, is obtained in the DA condition due to the strengthening effect of the precipitates, substructures, and dislocations. However, the high dislocation density, which coincides with the remaining cell structure, may also indicate that the temperature of the aging treatment is insufficient to reduce residual stresses. This might be important for larger and more complex parts exceeding the sample dimensions, where low residual stresses are needed to avoid deformation and cracking [35-37]. In contrast, prior SHTs relieve residual stresses due to higher temperatures [38-39]. Fine sub- structures with its $\mathrm{Nb}$-rich boundaries partly vanished and the dislocation density decreased, as shown in the local misorientation mappings of Fig. 4(c). Thus, small angle boundaries and dislocation hardening effects are reduced. An important effect of the SHTs, carried out between 930 and $1000^{\circ} \mathrm{C}$, is the homogenization of the $\mathrm{Nb}$ content, which is necessary for the formation of $\gamma^{\prime \prime}$-precipitates $\left(\mathrm{Ni}_{3} \mathrm{Nb}, \mathrm{DO}_{22}\right)$. Additionally, depending on the temperature of the SHT, different fractions of the $\delta$-phase are precipitated. At temperatures around 930 to $954^{\circ} \mathrm{C}$, a high amount of the $\delta$-plates is formed. Blockyshaped $\delta$ precipitates are primarily present at grain boundaries while shorter and thinner precipitates are found in the grain interior. Those in the grain interior can lead to precipitation strengthening; however, less $\mathrm{Nb}$ is available for the formation of strengthening $\gamma^{\prime \prime}$-precipitates during subsequent aging. This is also reflected by the strengths of the SHT930 and SHT954 conditions, which are less than the strength of the SHT1000 condition, where almost no $\delta$-phase was formed and thus high fractions of $\gamma^{\prime \prime}$ are likely. In addition, EBSD mappings of the grain structure and morphology (Fig. 3 ) showed that no grain coarsening occurred in all conditions. Thus, the highest tested SHT temperature of $1000^{\circ} \mathrm{C}$ is applicable for additively manufactured IN718. Compared to 

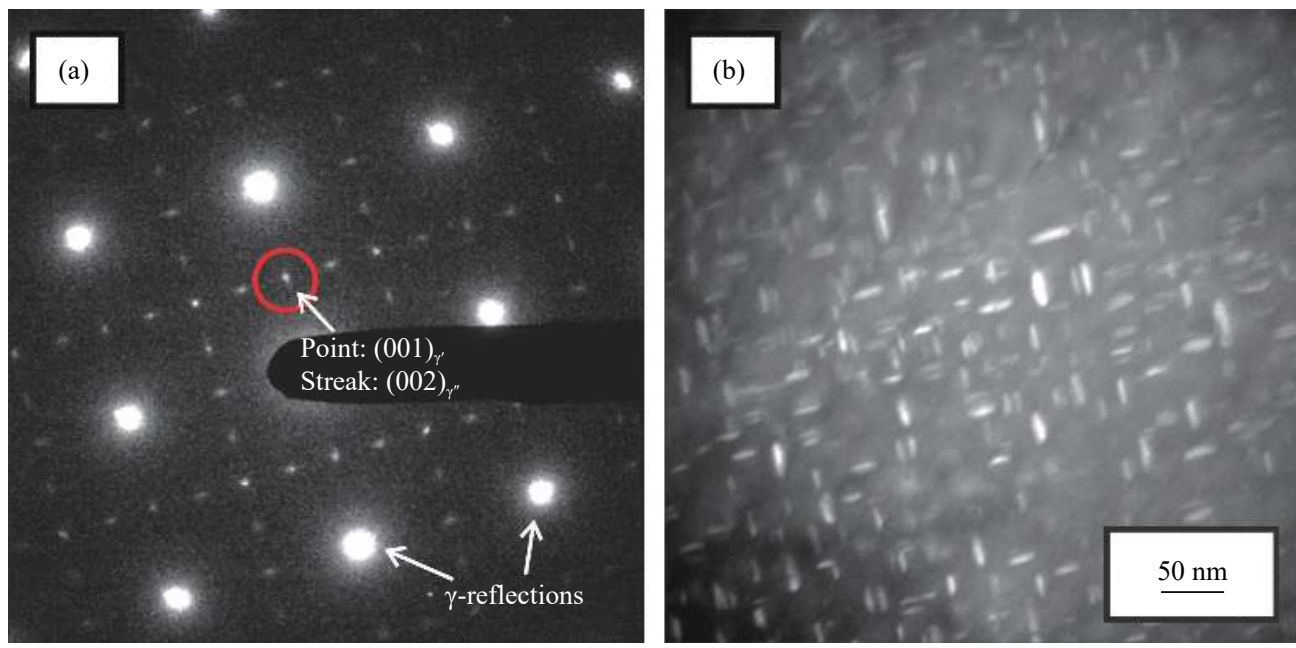

Fig. 5. TEM investigation of the SHT954 condition: (a) diffraction pattern with selected $(001)_{\gamma^{\prime}}(002)_{\gamma^{\prime \prime}}$ diffraction spot; (b) $\gamma^{\prime}$ - and $\gamma^{\prime \prime}$-precipitates in a TEM dark field image.
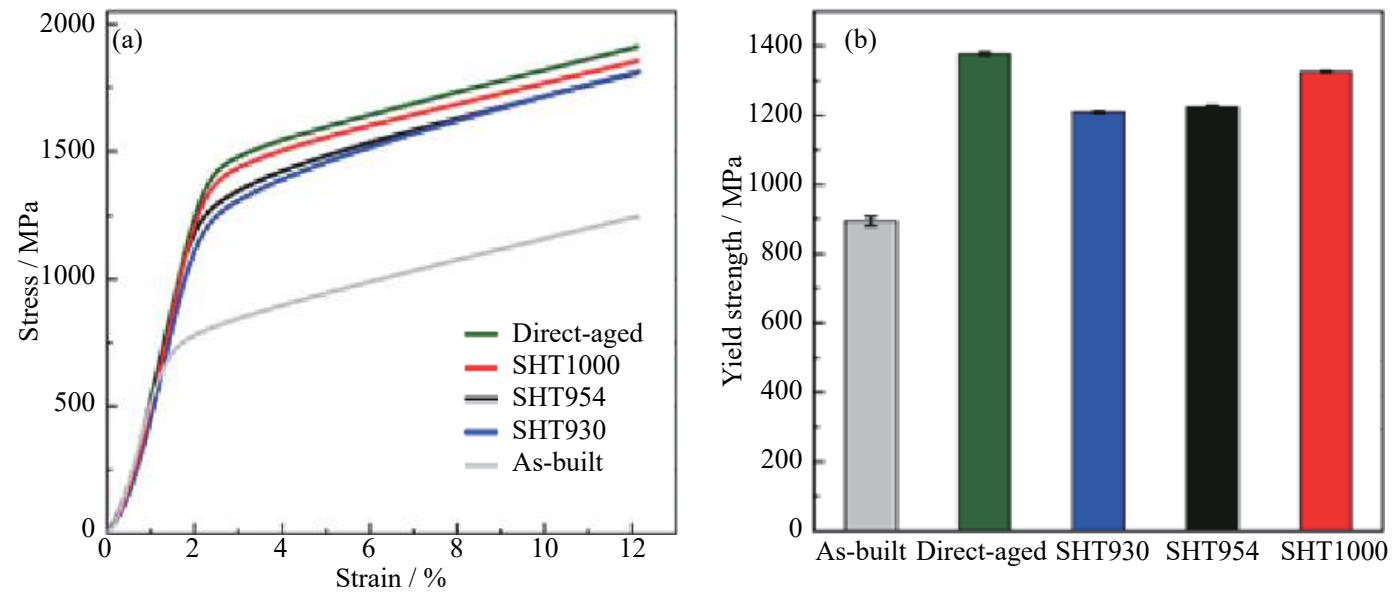

Fig. 6. (a) Stress-strain curves and (b) yield strengths of additively manufactured IN718 after different heat treatments, as examined by compression tests.

conventionally produced material, where high temperatures and deformations will lead to recrystallization and grain growth of the material, in this process the $\delta$-phase is not needed to prevent grain coarsening [40].

\section{Conclusions}

AM of IN718 by SLM affects the alloy microstructure due to high cooling rates and complex process parameters. The as-built condition shows columnar and equiaxed growth of dendrites and the segregation of $\mathrm{Nb}$ in the interdendritic regions. Subsequent heat treatments are very important for IN718 to dissolve Laves phases, homogenize the $\mathrm{Nb}$ content, reduce internal stresses, and form strengthening $\gamma^{\prime}$ - and $\gamma^{\prime \prime}$ precipitates. However, the conventional heat treatment should be adjusted to improve the microstructure and phase composition of the additively manufactured material. This work shows that two different approaches for heat-treating the materials can be conducted to achieve a maximum static strength.

(1) Direct aging leads to the highest compressive yield strength of $1377 \mathrm{MPa}$, because fine dendritic substructures and high dislocation densities are preserved at aging temperatures of $720^{\circ} \mathrm{C}$, while moderate volume fractions of $\gamma^{\prime}$ - and $\gamma^{\prime \prime}$-precipitates are obtained.

(2) A SHT at $1000^{\circ} \mathrm{C}$ causes the formation of the highest volume fractions of the strengthening $\gamma^{\prime}$ - and $\gamma^{\prime \prime}$-precipitates, as the $\mathrm{Nb}$-rich interdendritic regions and Laves phases are dissolved and less $\delta$-phase precipitated. In this case, the high SHT temperature leads to a slight coarsening of the dendritic substructure and a reduced dislocation density and thus, to a slightly lower strength than the DA condition. Compared with direct aging, a higher temperature might provide better stress relief.

At SHT temperatures between 930 and $954^{\circ} \mathrm{C}$ the $\mathrm{Nb}$ rich, plate-like $\delta$-phase is formed, reducing the fraction of the strengthening $\gamma^{\prime \prime}$-precipitates, which leads to the lowest static strength of the heat treated conditions. 


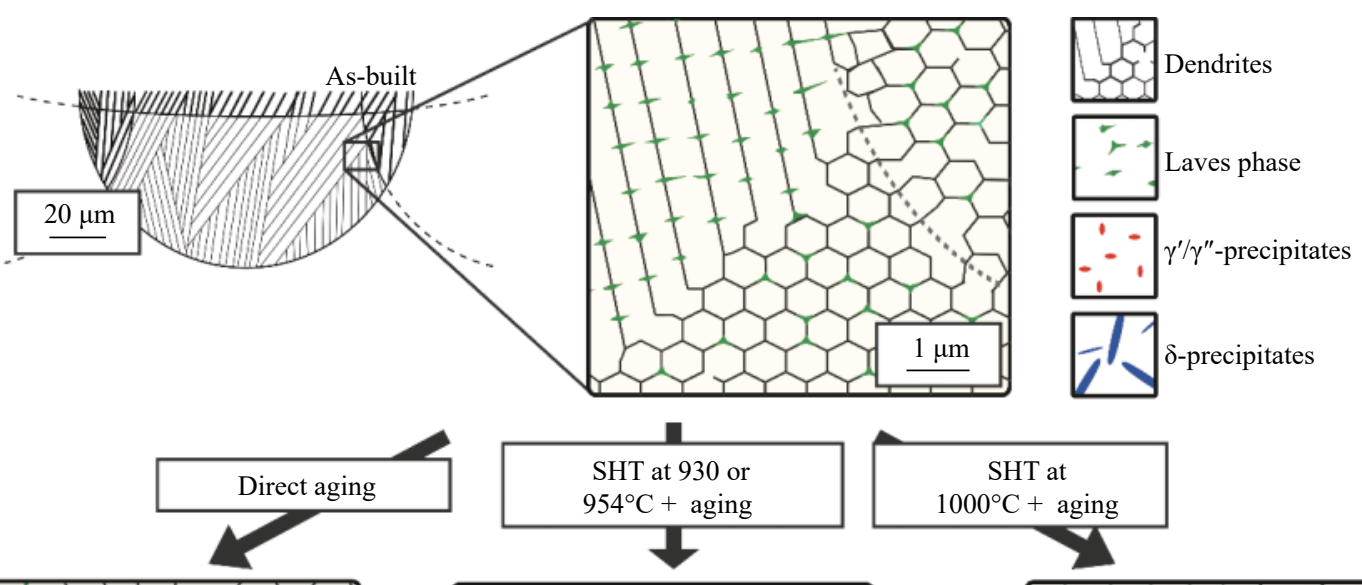

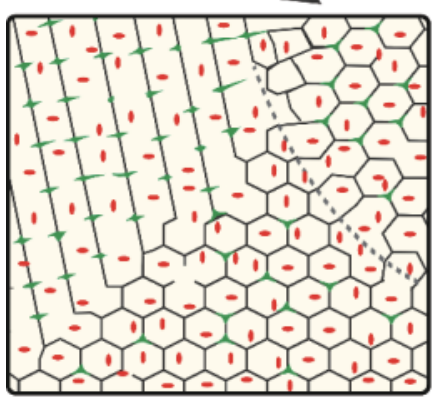

- Dendritic structure

- High dislocation density

- Laves phase

- Moderate amount of $\gamma^{\prime \prime}$-precipitates

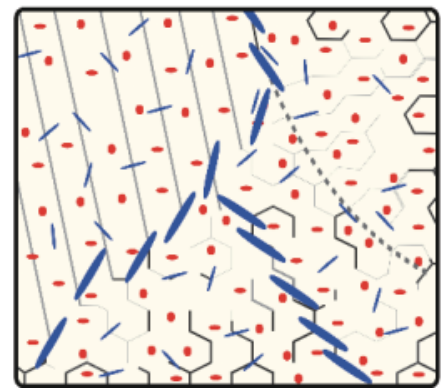

- Partly dissolved dendrites

- No Laves phase

- High fraction of $\delta$-phase

- Lowest amount of $\gamma^{\prime \prime}$-precipitates

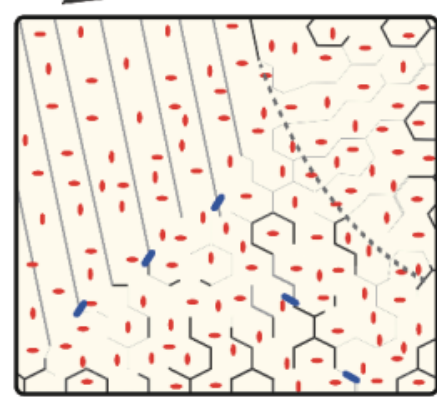

- Partly dissolved dendrites

- No Laves phase

- Minor fraction of $\delta$-phase

- Highest amount of

$\gamma^{\prime \prime}$-precipitates

Fig. 7. Schematic evolution of the microstructure and phases of IN718 manufactured by SLM.

\section{Acknowledgement}

We thank Lufthansa Technik AG (Hamburg, Germany) for the collaboration and the manufacturing of the additively manufactured samples.

Open access funding provided by Projekt DEAL.

Open Access This article is licensed under a Creative Commons Attribution 4.0 International License, which permits use, sharing, adaptation, distribution and reproduction in any medium or format, as long as you give appropriate credit to the original author(s) and the source, provide a link to the Creative Commons licence, and indicate if changes were made. The images or other third party material in this article are included in the article's Creative Commons licence, unless indicated otherwise in a credit line to the material. If material is not included in the article's Creative Commons licence and your intended use is not permitted by statutory regulation or exceeds the permitted use, you will need to obtain permission directly from the copyright holder. To view a copy of this licence, visit http://creativecommons.org/licenses/by/4.0/.

\section{References}

[1] L. Nickels, AM and aerospace: An ideal combination, Met. Powder Rep., 70(2015), No. 6, p. 300.
[2] S. Soller, R. Behr, F. Laithier, M. Lehmann, A. Preuss, and R. Salapete, Design and testing of liquid propellant injectors for additive manufacturing, [in] 7th European Conference for Aerospace Sciences, Milan, 2017, p. 306.

[3] N. Arjakine, J. Bruck, B. Grüger, D.M. Seeger, and R. Wilkenhoener, Advanced weld repair of gas turbine hot section components, [in] ASME Turob Expo 2008: Power for Land, Sea and Air, Berlin, 2008, p. 559.

[4] Q.B. Jia and D.D. Gu, elective laser melting additive manufacturing of Inconel 718 superalloy parts: Densification, microstructure and properties, J. Alloys Compd., 585(2014), p. 713.

[5] Y.S. Lee and W. Zhang, Modeling of heat transfer, fluid flow and solidification microstructure of nickel-base superalloy fabricated by laser powder bed fusion, Addit. Manuf., 12(2016), p. 178.

[6] N. Raghavan, R. Dehoff, S. Pannala, S. Simunovic, M. Kirka, J. Turner, N. Carlson, and S.S. Babu, Numerical modeling of heat-transfer and the influence of process parameters on tailoring the grain morphology of IN718 in electron beam additive manufacturing, Acta Mater., 112(2016), p. 303.

[7] P. Mercelis and J.P. Kruth, Residual stresses in selective laser sintering and selective laser melting, Rapid Prototyp. J., 12(2006), No. 5, p. 254.

[8] Y.P. Mei, Y.C. Liu, C.X. Liu, C. Li, L.M. Yu, Q.Y. Guo, and H.J. Li, Effect of base metal and welding speed on fusion zone microstructure and HAZ hot-cracking of electron-beam welded Inconel 718, Mater. Des., 89(2016), p. 964.

[9] T. Raza, K. Hurtig, G. Asala, J. Andersson, L.E. Svensson, and O.A. Ojo, Influence of heat treatments on heat affected zone cracking of gas tungsten arc welded additive manufactured al- 
loy 718, Metals, 9(2019), No. 8, p. 881.

[10] R. Mertens, B. Vrancken, N. Holmstock, Y. Kinds, J.P. Kruth, and J. Van Humbeeck, Influence of powder bed preheating on microstructure and mechanical properties of H13 tool steel SLM parts, Phys. Procedia, 83(2016), p. 882.

[11] B. Vrancken, S. Buls, J.P. Kruth, and J. Van Humbeeck, Preheating of selective laser melted Ti6Al4V: Microstructure and mechanical properties, [in] Proceedings of the 13th World Conference on Titanium, San Diego, 2016, p. 1269.

[12] Y. Lee, M. Nordin, S.S. Babu, and D.F. Farson, Effect of fluid convection on dendrite arm spacing in laser deposition, Metall. Mater. Trans. B, 45(2014), No. 4, p. 1520.

[13] P.W. Liu, Z. Wang, Y.H. Xiao, M.F. Horstemeyer, X.Y. Cui, and L. Chen, Insight into the mechanisms of columnar to equiaxed grain transition during metallic additive manufacturing, Addit. Manuf., 26(2019), p. 22.

[14] M. Pröbstle, S. Neumeier, J. Hopfenmüller, L.P. Freund, T. Niendorf, D. Schwarze, and M. Göken, Superior creep strength of a nickel-based superalloy produced by selective laser melting, Mater. Sci. Eng. A, 674(2016), p. 299.

[15] D.Y. Zhang, W. Niu, X.Y. Cao, and Z. Liu, Effect of standard heat treatment on the microstructure and mechanical properties of selective laser melting manufactured Inconel 718 superalloy, Mater. Sci. Eng. A, 644(2015), p. 32.

[16] W.M. Tucho, P. Cuvillier, A. Sjolyst-Kverneland, and V. Hansen, Microstructure and hardness studies of Inconel 718 manufactured by selective laser melting before and after solution heat treatment, Mater. Sci. Eng. A, 689(2017), p. 220.

[17] X.Q. Ni, D.C. Kong, Y. Wen, L. Zhang, W.H. Wu, B.B. He, L. $\mathrm{Lu}$, and D.X. Zhu, Anisotropy in mechanical properties and corrosion resistance of $316 \mathrm{~L}$ stainless steel fabricated by selective laser melting, Int. J. Miner. Metall. Mater., 26(2019), No. 3, p. 319.

[18] T. Vilaro, C. Colin, J.D. Bartout, L. Nazé, and M. Sennour, Microstructural and mechanical approaches of the selective laser melting process applied to a nickel-base superalloy, Mater. Sci. Eng. A, 534(2012), p. 446.

[19] Y.L. Kuo, S. Horikawa, and K. Kakehi, Effects of build direction and heat treatment on creep properties of Ni-base superalloy built up by additive manufacturing, Scripta Mater., 129(2017), p. 74.

[20] E. Chlebus, K. Gruber, B. Kuźnicka, J. Kurzac, and T. Kurzynowski, Effect of heat treatment on the microstructure and mechanical properties of Inconel 718 processed by selective laser melting, Mater. Sci. Eng. A, 639(2015), p. 647.

[21] H.E. Helmer, C. Körner, and R.F. Singer, Additive manufacturing of nickel-based superalloy Inconel 718 by selective electron beam melting: Processing window and microstructure, $J$. Mater. Res, 29(2014), No. 17, p. 1987.

[22] K.N. Amato, S.M. Gaytan, L.E. Murr, E. Martinez, P.W. Shindo, J. Hernandez, S. Collins, and F. Medina, Microstructures and mechanical behavior of Inconel 718 fabricated by selective laser melting, Acta Mater., 60(2012), No. 5, p. 2229.

[23] G.A. Rao, M. Kumar, M. Srinivas, and D.S. Sarma, Effect of standard heat treatment on the microstructure and mechanical properties of hot isostatically pressed superalloy inconel 718, Mater. Sci. Eng. A, 355(2003), No. 1-2, p. 114.

[24] S. Raghavan, B.C. Zhang, P. Wang, C.N. Sun, M.L.S. Nai, T. $\mathrm{Li}$, and J. Wei, Effect of different heat treatments on the microstructure and mechanical properties in selective laser melted INCONEL 718 alloy, Mater. Manuf. Processes, 32(2017), No. 14, p. 1588 .
[25] T. Antonsson and H. Fredriksson, The effect of cooling rate on the solidification of INCONEL 718, Metall. Mater. Trans. B, 36(2005), No. 1, p. 85.

[26] S. Azadian, L.Y. Wei, and R. Warren, Delta phase precipitation in Inconel 718, Mater. Charact., 53(2004), No. 1, p. 7.

[27] M. Sundararaman, P. Mukhopadhyay, and S. Banerjee, Some aspects of the precipitation of metastable intermetallic phases in INCONEL 718, Metall. Mater. Trans. A, 23(1992), No. 7, p. 2015.

[28] R. Cozar and A. Pineau, Morphology of $y^{\prime}$ and $y^{\prime \prime}$ precipitates and thermal stability of inconel 718 type alloys, Metall. Trans., 4(1973), No. 1, p. 47.

[29] H.J. Zhang, C. Li, Q.Y. Guo, Z.Q. Ma, H.J. Li, and Y.C. Liu, Improving creep resistance of nickel-based superalloy Inconel 718 by tailoring gamma double prime variants, Scripta Mater., 164(2019), p. 66

[30] M.A. Martorano and V.B. Biscuola, Columnar front tracking algorithm for prediction of the columnar-to-equiaxed transition in two-dimensional solidification, Modell. Simul. Mater. Sci. Eng., 14(2006), No. 7, p. 1225.

[31] J. Liu and A.C. To, Quantitative texture prediction of epitaxial columnar grains in additive manufacturing using selective laser melting, Addit. Manuf., 16(2017), p. 58.

[32] R. Acharya, J.A. Sharon, and A. Staroselsky, Prediction of microstructure in laser powder bed fusion process, Acta Mater., 124(2017), p. 360.

[33] X.M. Zhao, J. Chen, X. Lin, and W.D. Huang, Study on microstructure and mechanical properties of laser rapid forming Inconel 718, Mater. Sci. Eng. A, 478(2008), No. 1-2, p. 119.

[34] D.Y. Deng, J. Moverare, R.L. Peng, and H. Söderberg, Microstructure and anisotropic mechanical properties of EBM manufactured Inconel 718 and effects of post heat treatments, Mater. Sci. Eng. A, 693(2017), p. 151.

[35] T. Thiede, S. Cabeza, T. Mishurova, N. Nadammal, A. Kromm, J. Bode, C. Haberland, and G. Bruno, Residual stress in selective laser melted Inconel 718: Influence of the removal from base plate and deposition hatch length, Mater. Perform. Charat., 7(2018), No. 4, p. 1.

[36] N. Nadammal, S. Cabeza, T. Mishurova, T. Thiede, A. Kromm, C. Seyfert, L. Farahbod, C. Haberland, J.A. Schneider, P.D. Portella, and G. Bruno, Effect of hatch length on the development of microstructure, texture and residual stresses in selective laser melted superalloy Inconel 718, Mater. Des., 134(2017), p. 139.

[37] Y. Liu, Y.Q. Yang, and D. Wang, A study on the residual stress during selective laser melting (SLM) of metallic powder, Int. J. Adv. Manuf. Technol., 87(2016), No. 1, p. 647.

[38] J. Schneider, B. Lund, and M. Fullen, Effect of heat treatment variations on the mechanical properties of Inconel 718 selective laser melted specimens, Addit. Manuf., 21(2018), p. 248.

[39] M.D. Sangid, T.A. Book, D. Naragani, J. Rotella, P. Ravi, A. Finch, P. Kenesei, J.S. Park, H. Sharma, J. Almer, and X.H. Xiao, Role of heat treatment and build orientation in the microstructure sensitive deformation characteristics of IN718 produced via SLM additive manufacturing, Addit. Manuf., 22(2018), p. 479.

[40] Y. Desvallées, M. Bouzidi, F. Bois, and N. Beaude, Delta phase in Inconel 718: Mechanical properties and forging process requirements, [in] E.A. Loria, eds., Superalloys 718, 625, 706 and Various Derivatives, The Minerals, Metals \& Materials Society, Warrendale, 1994, p. 281. 